Trab. Ling. Aplic., Campinas, (43): 35-49, Jan./Jun. 2004

\title{
A PRÁTICA DE ANÁLISE LINGÜÍSTICA NO LIVRO DIDÁTICO: UMA PROPOSTA PÓS-PCN*
}

\author{
WAGNER RODRIGUES SILVA \\ (Doutorando em Lingüísta Aplicada - UNICAMP)
}

\begin{abstract}
In this paper we aim to examine how the linguistic analysis directives proposed by the National Curricular Parameters to the Portuguese Language Teaching are incorporated by Portuguese textbooks. The data shows that although the teacher's handbook suggests the development of the reflection literacy, some linguistic analysis exercises in the student's textbook still point to the development of the recognition literacy.

Keywords: Brazilian National Curricular Parameters, linguistic analysis, reflection and recognition literacy

"Os livros didáticos funcionam, então, como antenas da sociedade, incorporando para si a tarefa de estabelecer uma ponte entre as instâncias produtoras do conhecimento e o processo pedagógico, sistematizando e didatizando os saberes que a cada momento histórico se definem como necessários." (Britto, 2000 [1997]:253)
\end{abstract}

Concordando com a atribuição da função de antena da sociedade ao livro didático, apresentada na epígrafe acima, afirmamos que esse material didático pode estabelecer uma ponte entre as proposições dos Parâmetros Curriculares Nacionais de Lingua Portuguesa (doravante PCN) para o Ensino Fundamental II e as práticas efetivas de ensino de Língua Portuguesa, sistematizando a operacionalização das diretrizes propostas no documento, que, no momento atual da história da disciplina Língua Portuguesa, caracterizam os saberes julgados necessários para o uso adequado da língua nas atividades de interação social $^{1}$. Dado o exposto, o nosso objetivo neste texto é analisar a operacionalização das orientações concernentes à prática de análise lingüística propostas nos $\mathrm{PCN}$ em três coleções de livro didático que assumem as orientações do documento.

\footnotetext{
* Este trabalho, que é um recorte representativo das análises realizadas no terceiro capítulo de nossa dissertação de mestrado desenvolvida no Departamento de Lingüística Aplicada do IEL/UNICAMP (Silva, 2003), foi apresentado na sessão de comunicação intitulada A escrita que é objeto do letramento escolar, no $14^{\circ}$ Congresso de Leitura do Brasil - COLE - Campinas, 22-24/07/2003.

${ }^{1}$ Este trabalho contribui com as investigações referentes às práticas de reflexão sobre a escrita, desenvolvidas no âmbito do projeto integrado Práticas de escrita e de reflexão sobre a escrita em contextos de ensino (CNPq n. ${ }^{\circ}$ 520427/2002-5).
} 
Considerando as orientações dos PCN para a realização da prática de análise lingüística com textos pertencentes a diferentes gêneros, os exercícios de análise lingüística investigados nos livros didáticos correspondem às atividades que legitimam os textos injuntivos de diferentes gêneros como unidade de análise. Na discussão instaurada neste trabalho, observamos a noção de letramento assumida pelos PCN, pois, no texto do documento, esse referencial teórico está subjacente às orientações referentes às propostas de prática de escuta/leitura, de produção de texto oral/escrito e de análise lingüística, que, por sua vez, é o eixo da análise aqui desenvolvida.

O nosso interesse em trazer as atividades gramaticais com textos injuntivos em livros didáticos para as discussões científicas é justificado pela ausência de pesquisa, no campo dos estudos aplicados da linguagem, sobre o uso desses textos no ensino de língua materna. Somos favoráveis a uma abordagem mais significativa dos textos injuntivos nas atividades escolares, pois, como demonstra Rosa (2003), o uso desses textos nas práticas sociais diárias envolvendo a escrita é bastante expressivo, exigindo muitas vezes um conhecimento particularizado do usuário, o qual está relacionado à habilidade denominada, segundo Hasan (1996), de letramento reflexivo.

Neste artigo, afora a introdução e as considerações finais, procuramos sistematizar nossas discussões em três momentos. No primeiro, tecemos algumas considerações sobre as diretrizes apresentadas nos PCN. Para tanto, apresentamos uma discussão sintética sobre o sentido atribuído à expressão análise lingüística no documento, bem como sobre as diferentes concepções de gramática que podem ser depreendidas do texto. Nessa discussão, procuramos observar as relações conceptuais imbricadas entre o que as diretrizes compreendem por análise lingüística e por gramática. Considerando as contribuições para a investigação empreendida, acrescentamos às discussões instauradas pressupostos teóricos oriundos dos estudos do letramento desenvolvidos principalmente por pesquisadores australianos. No segundo momento, ainda caracterizando os documentos analisados neste trabalho, apresentamos uma descrição das coleções de livro didático selecionadas, uma vez que procuramos elucidar os pressupostos teórico-metodológicos referentes à prática de análise lingüística explicitados no manual do professor das coleções. Por fim, no terceiro momento, analisamos uma atividade de análise lingüística de cada coleção de livro didático. Enfatizamos que as atividades examinadas legitimam textos injuntivos de diferentes gêneros como unidade de análise e são representativas do trabalho de análise lingüística operacionalizado nas coleções.

\section{A PRÁTICA DE ANÁLISE LINGÜÍSTICA PROPOSTA PELOS PCN}

As atividades de análise lingüística, de acordo com os PCN, compreendem as atividades de reflexão sobre a língua em uso. Nesse sentido, o texto e o gênero de texto são legitimados como unidade e objeto de ensino, respectivamente. Os textos de diferentes gêneros utilizados em atividades de produção ou de leitura determinam os conteúdos lingüísticos a serem enfocados nas denominadas atividades de reflexão sobre a língua. $\mathrm{Na}$ página 27 do documento, lê-se que uma atividade de análise lingüística supõe o planejamento de situações didáticas que possibilitem a reflexão não apenas sobre os 
diferentes recursos expressivos utilizados pelo autor do texto, mas também sobre a forma pela qual a seleção de tais recursos reflete as condições de produção do discurso e as restrições impostas pelo gênero e pelo suporte.

Os PCN são taxativos ao afirmarem que a prática análise lingüística não é uma nova denominação para o ensino de gramática (p.78), pois, nessa prática, as dimensões pragmáticas e semânticas da linguagem precisam ser tratadas de forma articulada à dimensão gramatical. Sobre as diretrizes referentes à abordagem do conteúdo gramatical nas aulas de língua materna, esclarecemos que, num momento anterior à caracterização da denominada atividade de análise lingüística, os PCN destacam que o trabalho com o conteúdo gramatical não deve ser abandonado, pois a verdadeira questão, no bojo da discussão sobre o assunto, não seria o fato de se ensinar ou não gramática, mas o que, para que e como ensiná-la (p.28).

No âmbito da análise das diretrizes sobre o ensino de gramática apresentadas nos PCN, desenvolvida em nossa pesquisa de mestrado, observamos que quatro concepções de gramática originárias dos campos de estudos teóricos e aplicados da linguagem podem ser recuperadas no texto do documento. As concepções de gramática normativa e internalizada são mencionadas explicitamente, ao passo que duas acepções de gramática descritiva, restrita e ampla, são mencionadas implicitamente. No momento da tentativa de diferenciação das atividades de análise lingüística e do que é concebido por ensino de gramática, como vimos no parágrafo anterior, os PCN permitem a observação de uma concepção restrita de gramática descritiva, pressupondo uma abordagem sem pretensão prescritiva limitada ao mero trabalho de identificação e classificação de estruturas em níveis de análise inferiores ao do texto, daí os planos de análise semântico e pragmático serem apresentados como aspectos exteriores à concepção de gramática subentendida. Um ponto pacífico a respeito do ensino gramatical, no texto do documento, é a refutação da concepção de gramática normativa, bem como das práticas prescritivas subjacentes a essa concepção.

Ainda no tocante às concepções de gramática recuperadas no texto dos PCN, evidenciamos que, apesar de assumir de forma explícita que concebem gramática como o conhecimento que ofalante tem de sua linguagem (p.27), o que é denominado na literatura lingüística de gramática internalizada, uma abordagem gramatical descritiva ampla de cunho funcional subjaz às orientações basilares de práticas de linguagem a partir da diversidade de texto e de gênero propostas no documento. A prática de análise lingüística inspirada nos postulados da gramática descritiva funcional é configurada pela abordagem das marcas lingüísticas características dos diferentes gêneros de texto. A respeito dessa orientação dos PCN, destacamos que a investigação por nós desenvolvida dos livros didáticos está restrita às atividades de análise lingüística caracterizadas pela tentativa de operacionalização dessa abordagem gramatical a partir de textos que realizam diferentes gêneros.

De fato, a expressão análise linguiística para os PCN está circunscrita às atividades epilingüística e metalingüística. A atividade epilingüística, nas aulas de língua materna, pode ser definida como uma prática estimulada e consciente da linguagem, com variação dos recursos expressivos e formais, como meio de obter novos efeitos de sentido, é um trabalho sobre a própria linguagem, compara as expressões, transforma-as, experimenta novos modos de construção canônicos ou não, brinca com a linguagem (cf.: Moura, 
1992:103; Franchi, 1987:41). A atividade metalingüística, nas aulas de língua materna, pode ser caracterizada como a atividade em que se procura falar sobre a própria língua, descrevê-la em quadro nocional intuitivo ou teórico, seja pela teoria da gramática tradicional, seja pelos pressupostos teóricos contemporâneos da ciência da linguagem (cf. Moura, 1992:103; Franchi, 1987:42). Os PCN (p. 48-49) sugerem que o professor restrinja as atividades de análise lingüística às atividades denominadas epilingüísticas, podendo se deter mais nas atividades metalingüísticas nas últimas séries do Ensino Fundamental II.

Fazendo um paralelo das críticas ao ensino tradicional de gramática apresentadas pelos PCN, no contexto brasileiro, com as críticas mencionadas por Hasan (1996:388) sobre o mesmo assunto no contexto australiano, realçamos a oposição dos PCN ao que a autora mencionada denomina de letramento de identificação (recognition literacy) e letramento de ação (action literacy). A primeira acepção de letramento corresponde à habilidade que o sujeito possui para classificar ou nomear os elementos lingüísticos, enquanto que a segunda acepção está atrelada ao que Hasan (1996:400) denomina de pedagogia baseada no gênero (genre-based pedagogy). Para desenvolver esse tipo de letramento, enfatiza-se o ensino de modelos de textos representativos de um dado gênero, portanto prioriza-se o enfoque de aspectos estruturais, resultado na reprodução de modelos escolarizados.

Ainda fundamentados nos pressupostos teóricos apresentados pela autora australiana, destacamos que a prática de análise lingüística proposta pelos $\mathrm{PCN}$ objetiva proporcionar o desenvolvimento do que Hasan (1996:399) denomina de letramento reflexivo (reflection literacy). Partindo da abordagem gramatical descritiva de cunho funcional em textos de diferentes gêneros, a prática de análise lingüística dos PCN propõe-se a expandir a capacidade de monitoração das possibilidades de uso da linguagem, ampliando a capacidade de análise crítica do aluno (p.33). Em síntese, destacamos que as orientações dos PCN evidenciam uma tentativa de transformação das atividades escolares no intuito de aproximá-las das práticas efetivas de uso da escrita na sociedade, assim como propõe Kleiman (1997;1995) em estudos desenvolvidos no Brasil.

\section{A CARACTERIZAÇÃO DOS LIVROS DIDÁTICOS SELECIONADOS}

As três coleções do Ensino Fundamental II utilizadas nas análises desenvolvidas são Linguagem nova, elaborada por Faraco \& Moura; Português: linguagens, elaborada por Cereja \& Magalhães; e Português: uma proposta para o letramento, elaborada por Magda Soares. Como critério metodológico de análise, selecionamos, em cada coleção, uma atividade de análise lingüística com textos injuntivos de diferentes gêneros de texto. Esclarecemos que esses gêneros de texto pertencem, de acordo com Marcuschi (2002:24), ao domínio discursivo instrucional, definido como a grande esfera da atividade humana em que circulam os textos constituídos essencialmente pelo tipo injuntivo, cuja funcionalidade para Rosa (2003:21) passa por um processo social pelo qual a linguagem é usada por um produtor em função de permitir ao seu interlocutor executar ou adquirir um conhecimento sobre como executar uma determinada tarefa. 
As coleções Linguagem nova e Português: linguagens são edições reformuladas, estando a primeira coleção na $17^{\mathrm{a}}$ edição e a segunda coleção na $2^{\mathrm{a}}$ edição. A edição anterior de ambas as coleções foi submetida à avaliação do Programa Nacional do Livro Didático/ 2002 - PNLD. As duas coleções obtiveram os maiores conceitos atribuídos aos livros de língua portuguesa, receberam duas estrelas, caracterizando-as como livros didáticos recomendados pelo Ministério da Educação. A coleção Português: uma proposta para o letramento está em sua primeira edição, pois ela não é uma reedição da coleção anteriormente publicada por Soares, que foi amplamente adotada nas escolas de todo território nacional, portando não houve edição alguma dessa coleção submetida à avaliação do PNLD divulgada no ano de 2002.

Esclarecemos que, com exceção da coleção Linguagem nova, as outras duas assumem explicitamente a observação das orientações dos PCN. Todas as coleções explicitam no manual do professor a ineficácia de uma abordagem gramatical pautada exclusivamente numa concepção de gramática normativa. Defendem um ensino produtivo que possibilite a reflexão sobre os usos de elementos lingüísticos em textos escritos constitutivos de práticas sociais que envolvam a escrita. Inteiramos que apenas a coleção Português: uma proposta para o letramento assume explicitamente uma abordagem pedagógica pautada na noção de letramento.

\section{AS ATIVIDADES DE ANÁLISE LINGÜÍSTICA OPERACIONALIZADAS}

A análise dos livros didáticos nos mostrou que a forma de abordagem gramatical desenvolvida nos livros didáticos é a abordagem sistemática (Travaglia, 2003:57), pois os conteúdos gramaticais enfocados não são motivados pelas necessidades evidenciadas empiricamente nas produções textuais dos alunos, caracterizando uma abordagem assistemática ou aleatória, no dizer de Travaglia (2003:57). A escolha dos aspectos gramaticais a serem trabalhados nos livros didáticos é motivada por outros critérios eleitos pelos autores, muitos dos quais ditados pela tradição escolar.

A forma de entrada para o desenvolvimento da abordagem sistemática nas coleções Linguagem nova e Português: linguagens são os tipos de recursos lingüísticos (Travaglia, 2003:61), pois diferentes tópicos gramaticais, como as tradicionais classes de palavra, são selecionados e trabalhados minuciosamente. A forma de entrada para o desenvolvimento da abordagem sistemática na coleção Português: uma proposta para o letramento são as instruções de sentido (Travaglia, 2003:61), pois os mais diversos recursos lingüísticos que manifestam uma dada instrução de sentido são enfocados.

Transcrevemos abaixo a atividade proposta a partir do texto injuntivo da receita de Feijão tropeiro no livro da $7^{\text {a }}$ série da coleção Linguagem nova. A seção em que essa atividade está inserida é denominada de Gramática. Observemos a atividade seguinte: 
(1)

\section{EXERCÍCIO}

Leia a receita que segue, típica da cozinha gaúcha:

Feijão tropeiro

Ingredientes:

$500 \mathrm{~g}$ de feijão (exceto o preto)

2 paios

$50 \mathrm{~g}$ de bacon

3 folhas de louro

3 dentes de alho

2 pimentas-de-bode

1 cebola batida

2 cubos de tempero para feijão

$250 \mathrm{~g}$ de lingüiça pura de porco

$400 \mathrm{~g}$ de toucinho salgado

1 maço de couve

farinha de mandioca

Modo de fazer:

Cozinhe o feijão na panela de pressão, somente com água, os paios, o bacon e o louro. Quando cozido, o feijão deve ficar com pouco caldo e com os grãos inteiros. Refogue, em pouco óleo, as pimentas, o alho amassado e a cebola. Jogue sobre o feijão e acrescente os cubos de tempero. Deixe ferver.

À parte, frite a lingüiça e o toucinho salgado cortado em pequenos cubos. Reserve. Jogue dentro do feijão a couve cortada fininho e mexa com farinha de mandioca suficiente para ficar solto.

Coloque numa travessa e ponha, por cima, a lingüiça frita e o torresmo. Sirva quente. Tempo de preparo: $1 \mathrm{~h} 20 \mathrm{~min}$. Porções: 10

Terra, Terezinha. Todo dia uma delícia. São Paulo, Ática, 1993. p.148.

a. Identifique, nessa receita, todas as formas verbais do imperativo. cozinhe / refogue / jogue / acrescente / deixe / frite / reserve / jogue / mexa / coloque / ponha / sirva

$b$. Que pessoa gramatical o autor da receita utilizou? A terceira pessoa do singular: você.

c. Como se trata da receita de um prato gaúcho e no Rio Grande do Sul emprega-se a segunda pessoa do singular $-t u$-, reescreva a parte Modo de fazer da receita utilizando essa pessoa.

Lembre-se: você deve conjugar o verbo no presente do indicativo e retirar o s. cozinha / refoga / joga / acrescenta / deixa / frita / reserva / joga / mexe / coloca / põe / serve

(Faraco \& Moura, $7^{\text {a }}$ Série, p.163-164)

A atividade gramatical proposta ilustra uma prática claramente criticada pelos PCN (p.18) denominada de uso do texto como pretexto para o enfoque do conteúdo gramatical. 
Diferentemente da proposição de reflexão sobre a língua em situações de uso, como é salientado no manual do professor da coleção, a receita é utilizada para o desenvolvimento de exercício de identificação de verbos no modo imperativo, como é passível de constatação no enunciado da letra a (Identifique, nessa receita, todas as formas verbais do imperativo.). Uma outra questão que não ultrapassa o simples exercício de identificação de categorias gramaticais é a pergunta realizada na letra $b$ (Que pessoa gramatical o autor da receita utilizou?). Destacamos que a distância entre a atividade proposta e a prática efetiva de reflexão sobre a língua em situações de uso visando o letramento reflexivo é instaurada por não haver tentativa alguma de explicação da funcionalidade do uso dessas categorias identificadas no texto injuntivo do gênero receita culinária.

A desconsideração da noção de gênero textual torna-se patente na atividade solicitada no enunciado da letra c (Como se trata da receita de um prato gaúcho e no Rio Grande do Sul emprega-se a segunda pessoa do singular - tu -, reescreva a parte Modo de fazer da receita utilizando essa pessoa.), pois o uso do verbo na terceira pessoa, seguido do pronome você, é motivado pelo gênero receita culinária, assim como os usos de verbos no infinitivo e na terceira pessoa do singular do presente do indicativo, também encontrados em gêneros pertencentes ao domínio instrucional, independente dos usos lingüísticos nas diversas variedades regionais brasileiras, não excluindo obviamente a variedade gaúcha.

Não se justifica propor uma atividade enfocando variação lingüística quando o uso do elemento lingüístico na situação proposta torna-se irreal ou artificial, incompatível com as autênticas práticas de linguagem do cotidiano. Sobre o uso do modo imperativo no português falado na região Sul, destacamos a pesquisa realizada por Scherre (2002), a qual também abrangeu o uso desse modo verbal nas regiões Sudeste e Centro-Oeste. Nessa pesquisa, a autora afirma que quase dois terços da população dessas regiões usam a forma verbal correspondente à segunda pessoa do singular do modo imperativo sem fazer associação evidente com o pronome $t u$. A autora faz referência inclusive aos eventuais ou, até mesmo, freqüentes usos do $t u$ com a mesma forma verbal do pronome você. Considerando o resultado dessa pesquisa, acreditamos que a proposição da reescrita da parte intitulada Modo de fazer da receita de Feijão Tropeiro, visando a mudança do pronome você pelo pronome $t u$, não se sustenta. Scherre (2002:224) afirma que os fatos apresentados sobre o imperativo evidenciam que, se tomarmos a gramática normativa como referência, seremos obrigados a dizer que os cerca de 110 milhões dos falantes das regiões Sul, Sudeste e Centro-Oeste estão errando ao usar o imperativo na forma associada ao modo indicativo em aproximadamente $90 \%$ das vezes (destaque da autora).

No tocante à atividade gramatical a partir do texto injuntivo proposta na coleção Português: linguagens, observemos a receita de Vampiro enganado seguinte, inserida na subseção $O$ numeral na construção do texto, no livro da $5^{\mathrm{a}}$ série. Como veremos adiante, a atividade transcrita abaixo nos mostra que, diferentemente das questões propostas na atividade com a receita de Feijão tropeiro na coleção Linguagem nova, as questões de classificação ou identificação da categoria gramatical estudada no texto não se encerram em si mesmas, mas, no conjunto da subseção, elas corroboram a abordagem da funcionalidade da categoria gramatical no texto injuntivo do gênero receita culinária. Para tanto, observemos em seguida a atividade proposta a partir da receita de Vampiro enganado: 
(2)

Você já tomou um "vampiro enganado"? Essa é uma receita que o Menino Maluquinho inventou. Veja:

\author{
VAMPIRO ENGANADO \\ Ingredientes \\ 1 copo de suco de uva \\ 1 cenoura raspada e cortada em pedaços \\ 1 tomate maduro \\ 1 laranja descascada e cortada em pedaços, sem semente
}

\title{
Modo de Fazer
}

1- Coloque no liquidificador a laranja e a cenoura e triture bem.

2- Acrescente o tomate e o suco de uva.

3- Junte dois ou três cubos de gelo e uma colher de sopa de açúcar.

4- Desligue o aparelho e passe a bebida por um coador para retirar as fibras que tenham ficado. Sirva em copos altos.

(Ziraldo. O livro de receitas do Menino Maluquinho, cit., p.18.)

1. A receita é organizada em duas partes: a dos ingredientes e a do modo de fazer.

a) Que tipo de informação encontramos na primeira parte? A informação sobre os produtos necessários para fazer o "vampiro enganado".

b) E na segunda? A informação sobre o que fazer com esses produtos, ou seja, como fazer o "vampiro enganado".

1.Na primeira parte da receita, encontramos vários algarismos. Na sua opinião, por que foram empregados algarismos em vez de numerais? É mais fácil visualizar os algarismos; eles evitam enganos e organizam melhor as informações.

2. Num dos itens do Modo de fazer, encontramos alguns numerais.

a) Identifique-os. dois, três, uma

b) Por que você acha que o gelo e o açúcar não foram mencionados na parte Ingredientes? Resposta pessoal. Talvez porque sejam ingredientes que a maior parte das casas tem no dia-a-dia. coador".

1. Compare a palavra uma de "uma colher de sopa de açúcar" à palavra um de "um

a) Qual dessas palavras é numeral? Como você sabe isso? Uma de "uma colher de sopa de açúcar", pois ela inicia quantidade nesse item, do mesmo modo que dois e três em "dois ou três cubos de gelo".

b) Qual dessas palavras é artigo indefinido? Por quê? Um de "um coador", pois a palavra não expressa aqui a noção de quantidade; trata-se de um coador qualquer. 
1. As receitas em geral são textos que apresentam muitos algarismos ou numerais. Porque (sic) você acha que isso acontece? Porque o sucesso da receita depende de quantidades exatas.

(Cereja \& Magalhães, 5ª́rie, p.149-150)

O trabalho com o gênero receita culinária é iniciado com a abordagem da organização textual. O exame da primeira questão (A receita é organizada em duas partes: a dos ingredientes e a do modo de fazer. a) Que tipo de informação encontramos na primeira parte? b) E na segunda?) permite-nos observar que são trabalhadas a organização estrutural do texto, bem como a funcionalidade das duas partes que formam a receita. A discretização dessas duas partes subsidiam o trabalho com outros aspectos lingüísticos a serem enfocados nas questões subseqüentes.

A segunda questão (Na primeira parte da receita, encontramos vários algarismos. Na sua opinião, por que foram empregados algarismos em vez de numerais?) enfoca a funcionalidade do uso de algarismos na primeira parte da receita. A resposta dada no livro do professor a essa questão (É mais fácil visualizar os algarismos; eles evitam enganos $e$ organizam melhor as informações.) explicita a importância da utilização dos algarismos na organização das informações no texto injuntivo, pois a quantidade exata dos ingredientes precisa ser seguida, caso contrário o produto final da receita é comprometido.

Ainda em relação à função dos numerais, destacamos a informação apresentada num Boxe ${ }^{2}$ intitulado Para que servem os numerais? ao lado das questões propostas. Haja vista que, ao responder a pergunta utilizada como título do Boxe (Os numerais atendem a uma necessidade humana de expressar com precisão quantidades ou grandes numerais, de ordenar, de organizar. Caso não houvesse os numerais, já imaginou como seria difícil responder a uma simples pergunta como esta: “Quantos anos você tem?”.), discute-se a importância dessa classe gramatical na vida do usuário da língua, pois os numerais são essenciais para a explicitação de informações específicas nas interações lingüísticas.

A questão número três, mais precisamente o enunciado da letra a (Num dos itens do Modo de fazer, encontramos alguns numerais. a) Identifique-os.), é um exemplo de atividade de identificação de categoria gramatical, porém, como afirmamos anteriormente, com um propósito mais amplo dentro do conjunto da seção. Ainda assim, destacamos que essa questão seria mais produtiva se houvesse uma orientação específica que proporcionasse uma reflexão sobre a ordem das instruções na parte denominada Modo de Fazer. Inteiramos que, apesar dos numerais utilizados nessa parte serem cardinais, a seqüência de execução das instruções não é aleatória. A última seqüência instrucional (Desligue o aparelho e passe a bebida por um coador para retirar as fibras que tenham ficado. Sirva em copos altos.), por exemplo, em hipótese alguma, poderia anteceder qualquer uma das seqüências instrucionais explicitadas na receita.

No tocante à questão número quatro (Compare a palavra uma de "uma colher de sopa de açúcar” à palavra um de “um coador”. a) Qual dessas palavras é numeral?

${ }^{2}$ Segundo as orientações dos autores no manual do professor, os Boxes não chegam a constituir uma seção. São textos paralelos que ampliam o assunto abordado na seção em que estão inseridos e estabelecem relações entre o assunto e a vida do aluno. 
Como você sabe isso? b) Qual dessas palavras é artigo indefinido? Por quê?), caracterizamo-la como uma atividade de gramática reflexiva e gramática explícita, pois é solicitado aos alunos para analisar o uso das palavras uma e um na receita e classificá-las como artigo ou numeral, apresentando as justificativas necessárias.

A última questão, número cinco (As receitas em geral são textos que apresentam muitos algarismos ou numerais. Porque (sic) você acha que isso acontece?), encerra a atividade dando unidade ao conjunto da seção, pois pergunta de forma direta o porquê do uso expressivo de numerais na receita. Ao abordar o uso dessa classe gramatical na receita de Vampiro enganado, enfoca-se o que Bakhtin (2000[1979]) denomina de estilo lingüístico ou funcional do gênero receita culinária.

Na coleção Português: uma proposta para o letramento, o conteúdo gramatical enfocado a partir do texto de lei extraído do Estatuto da criança e do adolescente são os usos das formas verbais que expressam os aspectos semânticos de norma, ordem, conselho, apelo ou recomendação. Transcrevemos abaixo os dois últimos artigos do Estatuto da criança e do adolescente reproduzidos no livro da $7^{\text {a }}$ série. Observemos o excerto:

Art. 79. As revistas e publicações destinadas ao publico infanto-juvenil não poderão conter ilustrações, fotografias, legendas, crônicas ou anúncios de bebidas alcoólicos, tabaco, armas e munições, e deverão respeitar os valores éticos e sociais da pessoa e da família.

Art. 80. Os responsáveis por estabelecimentos que explorem comercialmente bilhar, sinuca ou congênere ou por casas de jogos, assim entendidas as que realizam apostas, ainda que eventualmente, cuidarão para que não seja permitida a entrada e a permanência de crianças e adolescentes no local, afixando aviso para orientação do público.

(Soares, $7^{\text {a }}$ Série, p.47)

No tocante às atividades propostas na seção Reflexão sobre a língua, autodenominadas pela coleção de atividades de gramática de uso, atentemos para a primeira parte da seção transcrita abaixo:

(4)

Leiam e discutam com a orientação do professor.

Recordem o Art. 74 do ECA:

"O poder Público, através do órgão competente, regulará [verbo no tempo FUTURO] as diversões e espetáculos públicos ..." [Formulação de uma ORDEM, de uma NORMA a ser cumprida.]

Compare com:

No Brasil, o Poder Público, através do órgão competente, regula [Verbo no tempo PRESENTE] as diversões e espetáculos públicos. [Enunciação de um FATO.] 
Observe este outro exemplo:

“Art.75. Toda criança ou adolescente terá acesso às diversões e espetáculos públicos classificado como adequados à sua faixa etária.” [Formulação de uma ORDEM, uma norma a ser cumprida.]

Compare com:

No Brasil, toda criança ou adolescente tem acesso às diversões e espetáculos públicos classificados como adequados à sua faixa etária. [Enuncia um FATO]

Respondam individualmente, em seus cadernos, às questões seguintes.

1. Verifique que frases você usaria em cada uma das situações a seguir:

a.Se alguém lhe perguntasse se o Art. 76 do ECAé respeitado, como você responderia? Escolha uma das frases e complete-a no seu caderno.

- Sim, as emissoras de rádio e televisão ... Ou:

- Não, as emissoras de rádio e televisão ... Sim, as emissoras de rádio e televisão somente exibem ... Ou: Não, as emissoras de rádio e televisão não exibem ...

b. Se alguém lhe perguntasse se o parágrafo único do Art. 78 do Estatuto da Criança e do Adolescente é respeitado, como você responderia? Escolha uma das frases e completea no seu caderno.

- Sim, as editoras ... Ou:

. Não, as editoras ... Sim, as editoras cuidam ... Ou: Não as editoras não cuidam ...

c.Se alguém lhe perguntasse se o Art. 79 do ECAé respeitado, como você responderia? Escolha uma das frases e complete-a no seu caderno.

- Sim, as respostas e publicações ... Ou:

- Não, as revistas e publicações ... Sim, as revistas e publicações [...] não contém ... Ou: Não, as revistas e publicações [...] contém ...

1. Transforme estas frases, que expressam fatos, em frases que expressam ordens, normas:

a.As locadoras somente alugam para crianças e adolescentes fitas adequadas à sua idade. As locadoras somente alugarão ...

b. Adolescentes não são admitidos em casas de jogos que realizam apostas. Adolescentes não serão admitidos ...

c.As fitas de vídeo sempre informam a faixa etária a que se destinam. As fitas de vídeo sempre informarão ...

d. As emissoras de tevê apresentam, no horário diurno, apenas programas adequados ao público infanto-juvenil. As emissoras de TV apresentarão ...

(Soares, 7ª Série, p.49-50)

A primeira parte transcrita da seção evidencia o enfoque no aspecto semântico do uso da forma verbo no futuro em função do texto injuntivo realizado no gênero estatuto. $\mathrm{O}$ trabalho proposto com o verbo no tempo futuro do modo indicativo expressando o sentido de norma ou ordem a ser cumprida é produtivo, haja vista que tais nuanças de sentido só 
são enfocadas nos livros didáticos a partir da abordagem do modo imperativo, evidenciando uma tradição da gramática escolar.

Chamamos a atenção para as situações criadas na questão número um, pois, como é afirmado na orientação para o professor ao lado do enunciado, além de objetivar aprofundar a compreensão do uso das formas verbais, é possibilitado ao aluno o posicionamento frente aos artigos do estatuto. O trabalho com a explicitação de metalinguagem não é enfatizado em momento algum nas duas questões propostas, o que nos permite caracterizá-las como autêntica atividade epilingüística.

A segunda parte da seção Reflexão sobre a língua transcrita adiante mantém o padrão da atividade gramatical operacionalizada na coleção. Atividades de gramática reflexiva são propostas partindo de recortes representativos do texto da unidade. Realçamos o enfoque dado ao modo imperativo, pois, considerando o uso que lhe é feito nas situações de interação criadas, a clássica definiç̧ão da tradição gramatical, passível de observação nas outras duas coleções, não é reproduzida. Nesta coleção, a acepção de conselho ou recomendação expressa pelo modo imperativo é enfocada, bem como a acepção de ordem ou norma expressa pelo uso do futuro do indicativo. Atentemos para a segunda parte da seção transcrita em seguida:

(5)

Leiam e discutam coma a orientação do professor.

". Retomem o Art.76 do Estatuto da Criança e do Adolescente:

“Art. 76. As emissoras de rádio e televisão somente exibirão, no horário recomendado para o público infanto-juvenil, programas com finalidades educativas, artísticas, culturais e informativas. [Uma ordem, uma norma a ser cumprida; verbo no futuro.]

* Suponham que um técnico do órgão competente do Poder Público esteja orientando a instalação de uma nova emissora de tevê; ele poderia dizer esta frase:

Somente exibam, no horário recomendado para o público infanto-juvenil, programas com finalidades educativas, artísticas, culturais e informativas. [Um conselho, uma recomendação; verbo no imperativo.]

. Observem este outro exemplo:

“Art. 77. Os proprietários, diretores, gerentes e funcionários de empresas que explorem a venda ou aluguel de fitas de programação em vídeo cuidarão para que não haja venda ou locação em desacordo com a classificação atribuída pelo órgão competente." [UMA ORDEM, UMA NORMA].

* Se o técnico anteriormente mencionado estivesse orientando a instalação de uma locadora, ele poderia dizer esta frase ao proprietário:

Cuide para que não haja venda ou locação em desacordo com a classificação atribuída às fitas pelo órgão competente. [UM CONSELHO, UMA RECOMENDAÇÃO].

Respondam individualmente, no caderno, às questões seguintes. 
1. Recorde as recomendações para a realização da atividade de Linguagem Oral, na p.48, prestando atenção nos verbos:

- Na exposição, não leiam anotações feitas pelo grupo, apenas orientem-se pelo roteiro.

- Exponham com clareza, com seriedade: não se trata de uma conversa com a turma, mas de uma apresentação formal da análise feita pelo grupo.

- Ouçam com atenção e respeito a exposição dos colegas.

- Durante as discussões, peçam a palavra e esperem sua vez de falar.

a.Reescreva essas recomendações com ordens, normas. Como exemplo, observe como ficaria a primeira:

Na exposição, os alunos não lerão anotações feitas pelo grupo, apenas se orientarão pelo roteiro. Os alunos exporão com clareza ... Os alunos ouvirão com atenção e respeito ... Durante as discussões, os alunos pedirão a palavra e esperarão sua vez de falar.

b. Compare as duas formas de apresentar as orientações para uma exposição aos colegas e responda: qual das duas formas você prefere? Por quê? Resposta pessoal. As preferências podem variar, porque os alunos podem construir diferentes sentidos para as frases, dependendo, entre outras coisas, de sua atitude em relação à situação escolar: submissão à autoridade (valorização da ordem, do comando) ou receptividade à orientação (preferência pela recomendação, pelo conselho).

(Soares, $7^{a}$ Série, p.50-51)

Nessa segunda parte da atividade sob análise, destacamos a atividade gramatical apresentada na questão número três, pois as próprias recomendações da atividade previamente proposta a partir do texto de lei, na seção Linguagem oral, são tomadas como unidade de análise. O enunciado $b$ (Compare as duas formas de apresentar as orientações para uma exposição aos colegas e responda: qual das duas formas você prefere? Por quê?) evidencia uma atividade de reflexão sobre a língua em uso de modo que, como salienta a orientação para o professor ao lado da questão, as preferências dos alunos pela forma do imperativo ou do futuro a fim de apresentar as orientações para uma exposição aos colegas podem variar, ademais eles podem construir diferentes sentidos para as frases, dependendo, entre outras coisas, de sua atitude em relação à situação escolar: submissão à autoridade (valorização da ordem, do comando) ou receptividade à orientação (preferência pela recomendação, pelo conselho). A forma de abordagem do modo imperativo nessas questões é bastante diferente da utilizada na coleção Linguagem Nova, cuja ênfase é dada às regras gramaticais de formação do modo verbal.

\section{CONSIDERAÇÕES FINAIS}

As atividades de análise lingüística a partir dos textos injuntivos propostas pelos livros didáticos examinados evidenciam três formas distintas de operacionalização das 
orientações dos PCN. Ainda que as orientações nos manuais do professor sinalizem a assunção de uma proposta de trabalho que vise ao desenvolvimento do que Hasan (1996) denomina de letramento reflexivo, algumas questões das atividades gramaticais nas duas primeiras coleções analisadas parecem corroborar para o que Hasan (1996) denomina de letramento de identificação. Na primeira coleção, o reconhecimento das categorias gramaticais é enfatizado; na segunda coleção, além da ênfase no reconhecimento das categorias gramaticais, a funcionalidade dos usos dessas categorias no texto de diferentes gêneros é priorizada. Quanto à última coleção analisada, o enfoque se restringe ao significado expresso pelas categorias gramaticais em função dos gêneros de texto em que estão inseridas, sem contemplação de atividades de identificação de categorias gramaticais.

Por fim, destacamos que, apesar do apego à abordagem da tradição escolar, as tentativas de inovação das atividades gramaticais são inquestionáveis, permitindo-nos, inclusive, questionar a validade para o momento pós-PCN da tese defendida por Bagno (2000) ao afirmar que o livro didático é um dos elementos responsáveis pela manutenção do ciclo vicioso no ensino de língua portuguesa. Acreditamos que, no momento pós-PCN, o livro didático ressurge como um elemento de suma importância para a desestabilização do ensino tradicional de gramática, para a renovação do ensino de língua materna. Em síntese, os dados revelam uma mudança em progresso, em construção.

\section{REFERÊNCIAS BIBLIOGRÁFICAS}

BAKHTIN, M. (1979). Estética da criação verbal. São Paulo, Martins Fontes. $3^{\text {a }}$ ed. 2000.

BAGNO, M. (2000). Dramática da língua portuguesa: tradição gramatical, mídia \& exclusão social. São Paulo: Loyola.

BRITTO, L. P. L. (1997). A sombra do caos: ensino de língua x tradição gramatical. Campinas/SP: ALB/ Mercado de Letras. 2000.

CEREJA, W. R.; MAGALHÃES, T. C. (2002). Português: linguagens. São Paulo: Atual. $5^{\mathrm{a}}, 6^{\mathrm{a}}, 7^{\mathrm{a}}$ e $8^{\mathrm{a}}$ séries. $2^{\mathrm{a} e d .}$

FARACO; MORA. (2002). Linguagem nova. São Paulo: Ática. 5 5 $^{\mathrm{a}}, 7^{\mathrm{a}} \mathrm{e} 8^{\mathrm{a}}$ séries. $17^{\mathrm{a}} \mathrm{ed}$.

FRANCHI, C. (1987). Criatividade e gramática. In.: Trabalhos em lingüística aplicada. Campinas: UNICAMP/ IEL. ${ }^{\circ}$ 9. p.5-45.

HASAN, R. (1996). Literacy, everyday talk and society. In.: Ruqaiya Hasan \& Geoff Williams. (orgs.) Literacy in society. London/New York: Longman. p.377-424.

KLEIMAN, A. B. (1997). Análise e produção de textos. In.: Maria T. G. Pereira (org.) Língua e linguagem em questão. Rio de Janeiro: Editora da UERJ. p. 261-283.

(1995). (org.). Os significados do letramento. Campinas, Mercado de Letras.

MARCUSCHI, L. A. (2002). Gêneros textuais: definições e funcionamento. In.: Angela Dionisio; Anna R. Machado \& Maria A. Bezerra. (org.). Gêneros textuais \& ensino. Rio de Janeiro: Lucerna. p. 19-36. 
Trabalhos em Lingüística Aplicada (43) - Jan./Jun. 2004

MOURA, H. M. de M. (1992). Análise crítica do artigo "criatividade e gramática" de Carlos Franchi. In.: Cadernos de Estudos Lingüísticos. Campinas: UNICAMP/IEL. n 22. p. 97-107.

PARAMETROS CURRICULARES NACIONAIS. (1998). Ensino Fundamental II. Brasília: MEC.

PROGRAMA NACIONAL DE LIVROS DIDÁTICOS. (2001). Guia de livros didáticos: $5^{a}$ a $8^{a}$ série. PNLD 2002. Brasília: MEC/SEF/FNDE.

ROSA, A. L. T. (2003). A seqüência injuntiva passo a passo. Dissertação de mestrado. Recife/PE: UFPE/CAC.

SCHERRE, M. M. P. (2002). A norma do imperativo e o imperativo da norma: uma reflexão sociolingüística sobre o conceito de erro. In: Marcos Bagno. (org.) Lingüística da norma. São Paulo: Edições Loyola. p. 217-251.

SILVA, W. R. (2003). Gramática no texto injuntivo: investigando o impacto dos PCN. Dissertação de Mestrado. Campinas: UNICAMP/IEL/DLA.

SOARES, M. (2002). Português: uma proposta para o letramento. São Paulo: Moderna. $5^{\mathrm{a}}, 6^{\mathrm{a}}, 7^{\mathrm{a}} \mathrm{e} 8^{\mathrm{a}}$ séries.

TRAVAGLIA, L. C. (2003). Gramática: ensino plural. São Paulo: Cortez. 